\title{
RELATIONSHIPS BETWEEN TROPOSPHERIC WATER VAPOR AND SURFACE TEMPERATURE AS OBSERVED BY RADIOSONDES
}

\author{
Dian J. Gaffen ${ }^{1,2}$, William P. Elliott ${ }^{1}$ and Alan Robock ${ }^{2}$
}

\begin{abstract}
Using radiosonde data from 50 stations for 19731990 , we quantify relationships between surface air temperature $\left(T_{s}\right)$ and precipitable water vapor $(W)$ for different time scales. Monthly mean observations are fairly well described by an equation of the form $\ln W=A+B T_{\mathrm{s}}$, but the coefficients $A$ and $B$ depend on the $T_{\mathrm{s}}$ range considered. At high $T_{\mathrm{s}}$ the relationship is poor. This relationship and relationships between sea surface temperature (SST) and $W$ based on satellite microwave observations over oceans are in remarkably good agreement over restricted SST ranges. Monthly and annual anomalies of $W$ and $T_{\mathrm{s}}$ are well correlated only outside the tropics, but on longer time scales, there is some evidence of positive trends in both $W$ and $T_{\mathrm{s}}$ at most of the stations studied. Thus the relationship between $W$ and $T_{\mathrm{s}}$ depends on the time scales and geographic region considered.
\end{abstract}

\section{Introduction}

The water vapor-greenhouse feedback is considered the strongest positive feedback in the climate system. Recent climate model simulations [Rind et al., 1991; del Genio et al., 1991; Shine and Sinha, 1991] lend theoretical support to a positive feedback among surface temperature, tropospheric water vapor and the greenhouse effect.

Observational studies of the feedback [Raval and Ramanathan, 1989; Stephens and Greenwald, 1991; Duvel and Bréon, 1991] have relied on correlations between satellite measurements of column water vapor, or precipitable water $(W)$, over open oceans and sea surface temperatures $(S S T)$. One might expect the relationship between $W$ and $S S T$ or surface air temperature $\left(T_{\mathrm{s}}\right)$ to resemble an exponential form, because saturation vapor pressure increases roughly exponentially with temperature, and therefore an equation of the form

$$
\ln W=A+B T_{s}
$$

should apply. Such equations (but for $S S T$, not $T_{s}$ ) were used by Raval and Ramanathan [1989] and Stephens and Greenwald [1991] to quantify the greenhouse effect of atmospheric water vapor. Those studies were based on satellite scanning multichannel microwave radiometer (SMMR) $W$ measurements available for open ocean areas for the period 1979-1983, although Raval and Ramanathan [1989] used only one month of $W$ data. Using two years of $W$ data from the special sensor microwave imager, Duvel and Bréon [1991] demonstrated the importance of using simultaneous measurements of $W$ and $S S T$ to derive relationships between them, and showed that the slope of the linear regression of $\ln W$ and $S S T$ varies with latitude. Inoue [1990] also showed that $W$ and $S S T$ are related differently in the intertropical and the South Pacific convergence zones.

\footnotetext{
${ }^{1}$ NOAA/ERL, Air Resources Laboratory, Silver Spring Maryland

'Department of Meteorology, University of Maryland, College Park Maryland

Copyright 1992 by the American Geophysical Union.
}

Paper number 92GL02001

0094-8534/92/92GL-02001\$03.00
Global radiosonde data, from continental and island stations, offer an opportunity to examine the relationships over a wider temperature range, for a longer period, and with spatially and temporally consistent data, because radiosonde reports yield both $W$ and $T_{s}$. In the following sections, we describe such a data set, and present relationships between $W$ and $T_{s}$ for both monthly mean data and monthly and annual anomalies. Trends in both variables are also presented.

\section{Data}

Twice-daily radiosonde reports for the period 1973-1990 from 50 stations (Table 1) were used to compute $W$ as the vertical integral of specific humidity from the surface to 500 $\mathrm{mb}$. Monthly means of $W$ and $T_{\mathrm{s}}$ were computed for both 0000 and 1200 UT observations, when available. Inspection of the time series at each station and historical information about the radiosonde stations revealed inhomogeneities in the records of about half of the stations, due to changes in instrumentation. To avoid making corrections to the data, the records of these stations were shortened to include only the most recent period of 4 or more years of homogeneous observations (Table 1). A more complete description of the data set is given by Gaffen [1992].

\section{Results and Discussion}

\section{Mean Monthly Precipitable Water and Temperature}

Combining mean monthly $W$ and $T_{\mathrm{s}}$ data for all stations, we find a general increase in $W$ with $T_{s}$ for $T_{\mathrm{s}}$ from about 238 to $302 \mathrm{~K}$ (Figure 1a). Between 302 and $312 \mathrm{~K}$ there is much more scatter in the data; these warmest temperatures are associated with $W$ values ranging from 10 to $50 \mathrm{~kg} \mathrm{~m}^{-2}$. On a logarithmic plot (Figure 1b), there is a suggestion of a general linear increase of $\ln (W)$ with $T_{s}$; the linear correlation coefficient $r$ between $I n(W)$ and $T_{s}$ for all the data is 0.94 (Table 2).

The linear increase of $\ln (W)$ with $T_{\mathrm{s}}$ is not valid for all $T_{\mathrm{s}}$ ranges. A least-squares linear regression line based on the data for $T_{\mathrm{s}}<273 \mathrm{~K}$ (obviously not over open ocean areas) has smaller slope than at higher $T_{s}$. The data from stations poleward of $20^{\circ}$ latitude show a strong relationship between $\ln (W)$ and $T_{\mathrm{s}}$ (Figure $1 \mathrm{~b}$ ), but tropical data show a much poorer correlation (Figure 1c). Most of the scatter is because there are large seasonal and geographic variations in tropical $W$ but only small $T_{\mathrm{s}}$ variations. The concentrated mass of points in Figure 1c with $T_{\mathrm{s}}$ between 295 and $305 \mathrm{~K}$ and $\ln (W)$ between 3 and 4 is from island stations in the tropical Pacific Ocean, where seasonal $T_{\mathrm{s}}$ variations are minimal, but substantial $W$ increases occur above the boundary layer during the convective season [Gaffen et al., 1992]. The outlying points are from continental stations in Africa, where both $T_{s}$ and $W$ are more variable but still not well correlated. The correlation coefficient between $\ln (W)$ and $T_{\mathrm{s}}$ for $T_{\mathrm{s}}>290 \mathrm{~K}$ in the tropics is 0.16 (for 2343 data pairs), compared with 0.61 for non-tropical stations (1069 pairs) both significant above the $99.9 \%$ confidence level.

Regression coefficients of $W$ and $T_{s}$ computed from the radiosonde data are remarkably close to those derived from satellite data and SST [Raval and Ramanathan, 1989; Stephens, 1990], for the ranges for which the latter regressions were made (Table 2 and Figure 2). The regression to the radiosonde data over the $T_{\mathrm{s}}$ range 273-304 
Table 1. List of stations and data period used. For stations with at least 10 years of homogeneous observations, trends in surface temperature $T_{s}\left(\mathrm{~K}_{\text {decade }}{ }^{-1}\right)$ and surface-to-500mb precipitable water $W\left(\mathrm{~kg} \mathrm{~m}^{-2}\right.$ decade $\left.^{-1}\right)$, for 0000 and 1200 UT are shown. Underlined trends are significantly different from zero, based on a two standard deviation range about the estimate.

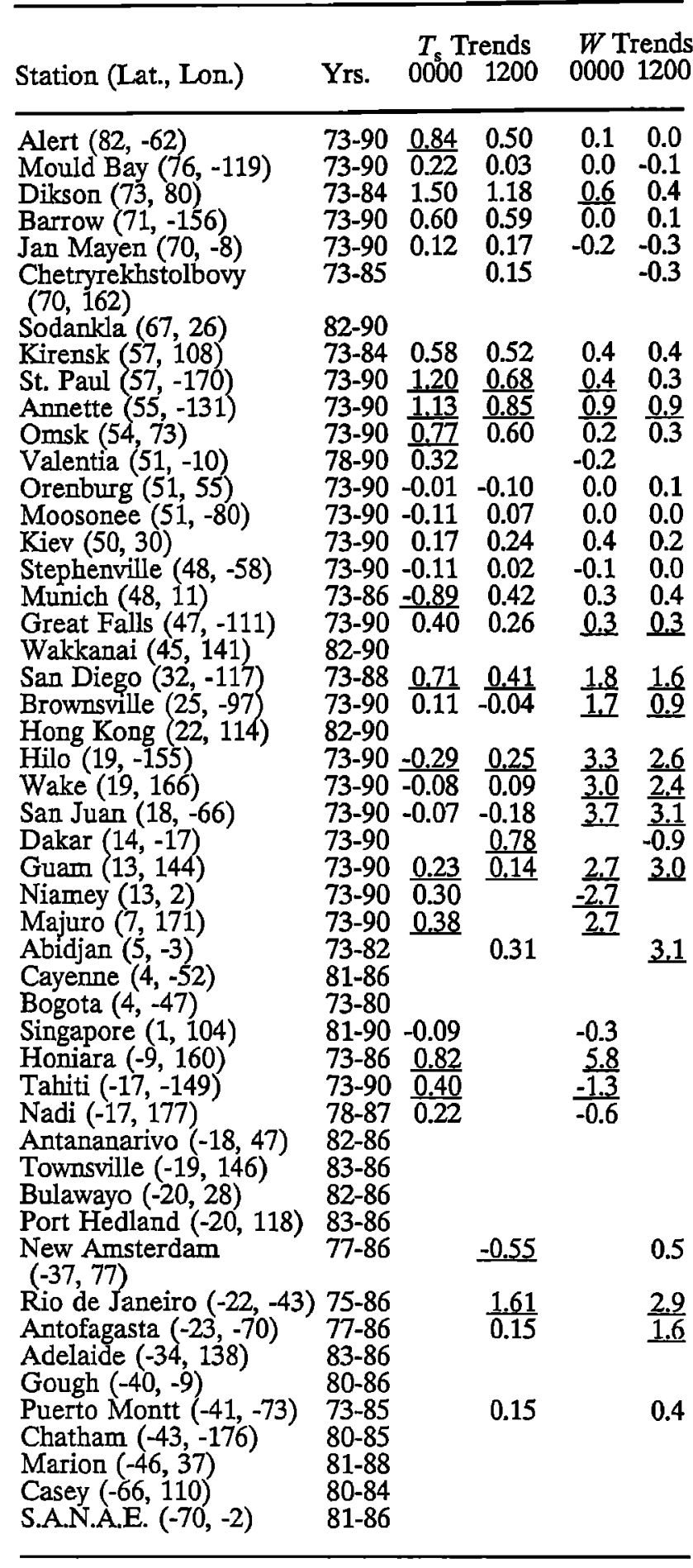

$\mathrm{K}$ gives values of $W$ only 3 to $5 \%$ larger than Raval and Ramanathan's [1989] estimate, and the regression for 288$304 \mathrm{~K}$ gives values typically $12 \%$ smaller than Stephens's [1990]. At lower temperatures, outside their ranges of applicability, both satellite-based equations underestimate the $W$ determined from radiosonde data by at least $15 \%$, and the difference increases with decreasing $T_{\mathrm{s}}$ (Figure 2).

For several reasons, the good agreement of the regressions at high $S S T$ might not have been anticipated, even though
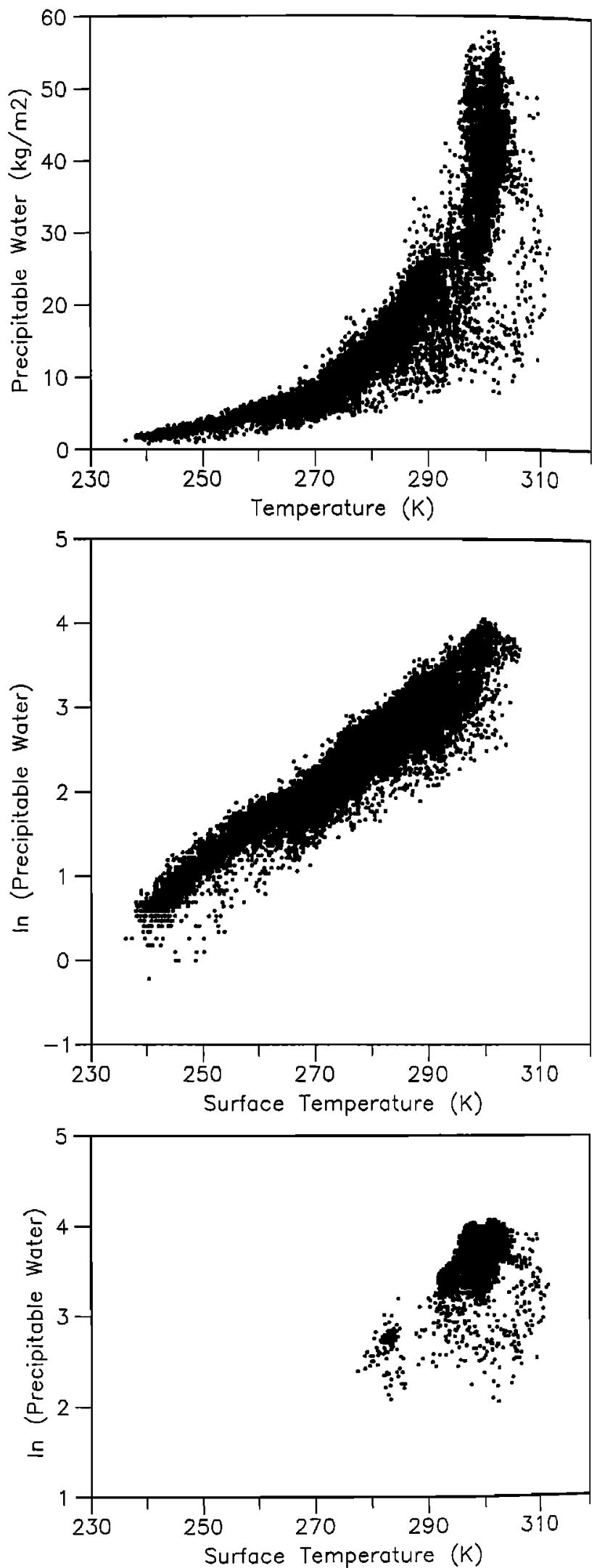

Fig. 1. Relationships between surface air temperature $T_{\text {f }}$ and precipitable water $W$. (a) Monthly mean $W$ plotted against $T_{\mathrm{s}^{-}}$(b) Same data as in (a), but $W$ is on a log scale, for stations poleward and (c) equatorward of $20^{\circ}$ latitude.

satellite data are calibrated with radiosonde observations. First, although the satellite is calibrated for the total column of water vapor, we truncated the radiosonde data at $500 \mathrm{mb}$ due to data quality issues [Elliott and Gaffen, 1991], so the 
Table 2. Coefficients, and their standard deviations, from linear regression of monthly mean values of surface air temperature $T_{\mathrm{s}}(\mathrm{K})$ with the logarithm of surface-to- $500 \mathrm{mb}$ precipitable water $W\left(\mathrm{~kg} \mathrm{~m}^{-2}\right)$, linear correlation coefficients $r$ and number of data points $N$, for several temperature ranges.

\begin{tabular}{llllll}
\hline TRange & $A$ (s.d.) & $\begin{array}{l}B \text { (s.d.) } \\
(\times 100)\end{array}$ & $r$ & $N$ & Source \\
\hline
\end{tabular}

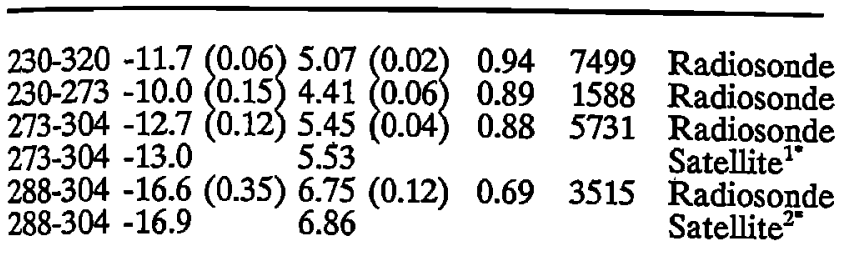

Raval and Ramanathan [1989]

${ }^{2}$ Stephens [1990]

The satellite-derived equations for sea surface temperature, not $T_{s}$, are shown for comparison.

satellite estimates of $W$ should be slightly higher. Second, the satellite data are for ocean areas only, whereas the radiosonde stations include continental and island sites. Last, $S S T$ is likely to be different from $T_{s}$ measured at radiosonde stations; a $1^{\circ} \mathrm{C}$ air-sea temperature difference would account for a $W$ difference of only about $1 \mathrm{~kg} \mathrm{~m}^{-2}$. Evidently, the overall effect of these differences is small.

Thus relationships between sea surface temperature (SST) and $W$ derived from SMMR measurements agree fairly well with the radiosonde data over the temperature ranges for which they were developed. However, like Duvel and Bréon [1991], we find the coefficients $A$ and $B$ in equation (1) to differ geographically. Given that different microwave $W$ retrieval algorithms show the poorest agreement among themselves over high SST regions [Tjemkes et al, 1991], extrapolating satellite-based regressions to higher temperatures may pose problems. Extrapolation to land areas is dangerous because over land high $T_{s}$ can be associated with a wide range of $W$ values.

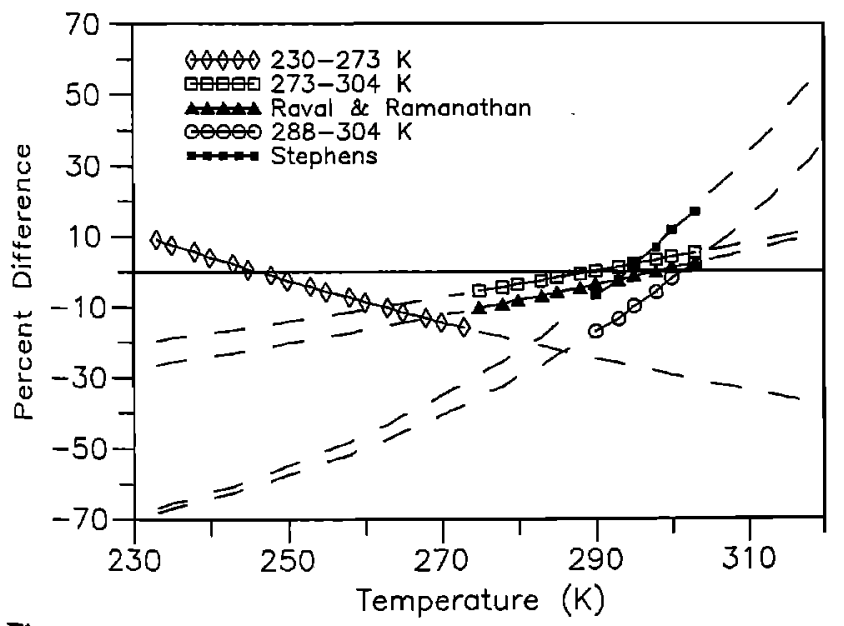

Fig. 2. Percentage differences between precipitable water predicted by the regressions to the radiosonde data over three temperature ranges (230-273 K, 273-304 K and 288$304 \mathrm{~K}$ ) and the regression for the complete temperature range $(230-320 \mathrm{~K})$. Satellite-derived relationships from Raval and Ramanathan [1989] and Stephens [1990] are shown for comparison. Symbols indicate the temperature range for which the regressions were developed; extrapolations are dashed.
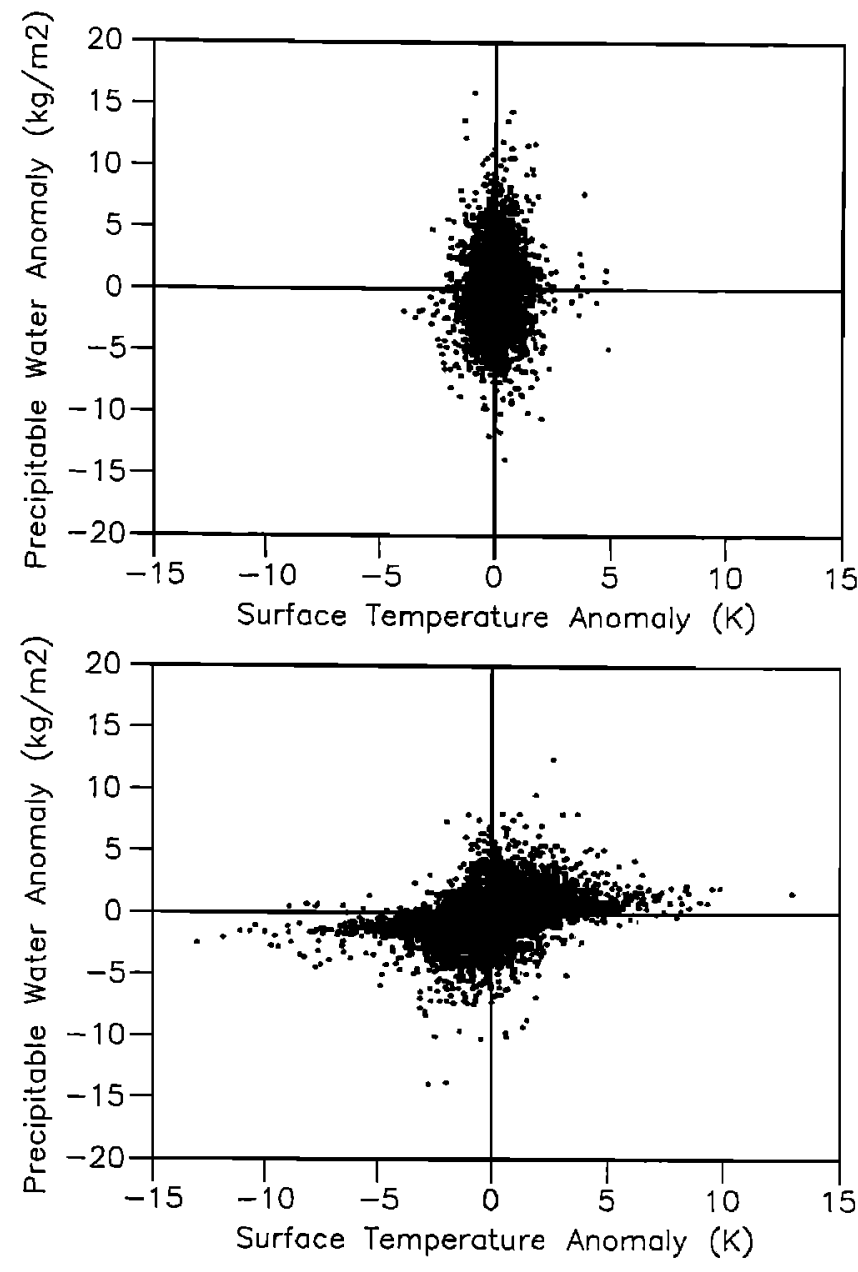

Fig. 3. Monthly anomalies of precipitable water and surface air temperature for (a) stations equatorward of $20^{\circ}$ latitude and (b) stations poleward of $20^{\circ}$ latitude.

\section{Anomalies of Precipitable Water and Temperature}

If relationships between $T_{s}$ or $S S T$ and $W$ are to be used in discussing climate feedbacks and long-term climate change, then it may be better to examine how interannual variations of monthly anomalies of $W$ and $T_{\mathrm{s}}$ are related than how $W$ varies with $T_{\mathrm{s}}$ anmually or geographically. Overall, the correlation between monthly $T_{\mathrm{s}}$ and $W$ anomalies is not large $(r=0.24)$, but the low correlation is due to tropical data (Figure 3a). In the tropics, large fluctuations in $W$ occur with very small $T_{\mathrm{s}}$ variations, yielding $r=0.04$, not significantly different from zero.

At higher latitudes, $W$ is positively correlated with $T_{s}$ $(r=0.38)$. Concealed within the scatter diagram (Figure $3 b$ ) are strong relationships between $W$ and $T_{\mathrm{s}}$ anomalies at individual stations. Slopes of linear regressions between monthly anomalies of $W$ and $\mathrm{T}_{\mathrm{s}}$ are all positive for stations with mean surface temperature $\left\langle T_{s}\right\rangle$ below about $295 \mathrm{~K}$ (Figure 4a), and the slopes increase with $\left\langle T_{s}\right\rangle$, as one might expect. Indeed, examination of individual station data indicates that, in Figure $3 \mathrm{~b}$, much of the scatter is due to station-to-station, not month-to-month, differences in the strength of the $W-T_{\mathrm{s}}$ relationship. At higher $\left\langle T_{\mathrm{s}}\right\rangle$, in the tropics, the uncertainty in the slope estimates is much larger (Figure $4 \mathrm{a}$ ), and at the highest $\left\langle T_{s}\right\rangle$ they are not different from zero to within two standard deviations.

We can only speculate on the physical causes of the strong relationship between $W$ and $T_{s}$ anomalies in mid- and high latitudes. Plausible mechanisms include (1) monthly 
variations in circulation patterns that lead to advection of warm-moist or cool-dry air at a given station; (2) variations in the radiative forcing of $T_{\mathrm{s}}$ due to $W$ variations; (3) radiative effects of cloudiness anomalies associated with $W$ anomalies; and (4) changes in evaporation that are positively correlated with $T_{\mathrm{s}}$ variations. The second, third and fourth mechanisms relate to the water vapor-greenhouse feedback, but the first depends on atmospheric flow.

Supposing that the effects of changes in greenhouse effect might become more evident at longer time scales, we computed annual anomaties of $W$ and $T_{s}$ and the slopes of the resulting linear regressions. If anomalous flow patterns dominate month-to-month variations but have less impact on year-to-year variations, the annual data would likely show a different relationship between $W$ and $T_{\text {s. }}$. For this analysis, we required at least 10 years of homogeneous observations from each station included, so there are fewer data points than in the monthly anomaly analysis. There is larger uncertainty in the slope estimates from the annual anomalies, compared with the monthly anomalies, because of the reduction in the number of independent data pairs. Nevertheless, at low $\left\langle T_{\mathrm{s}}\right\rangle$ the slopes are remarkably similar (Figure 4). At high $\left\langle T_{s}^{s}\right\rangle$, the slopes are higher for annual anomalies than for monthly anomalies, but because of the larger uncertainty, there is still no clear relationship. Thus, we have no evidence that the relationship between anomalies of $W$ and $T_{\mathrm{s}}$ is significantly different on the month-to-month and year-to-year time scales.

If radiative effects dominate over advective effects on the year-to-year time scale, these results are consistent with a water vapor-greenhouse feedback in mid- and high-latitudes, but not in the tropics, where other processes must dominate both monthly and annual anomalies. A possible explanation is that the water vapor-greenhouse feedback in the tropics is determined more by water vapor at higher elevation than is the case at higher latitudes, where lower temperatures mean air can hold less moisture. If so, good observations above $500 \mathrm{mb}$ will be required to identify a relationship between $T_{\mathrm{s}}$ and water vapor. On the other hand, uppertropospheric water vapor anomalies are likely related to anomalies in large-scale circulation patterns and deep convection in the tropics, which have been shown to be poorly correlated with $S S T$, especially over the warmest ocean regions [Graham and Barnett, 1987; Inoue, 1990].
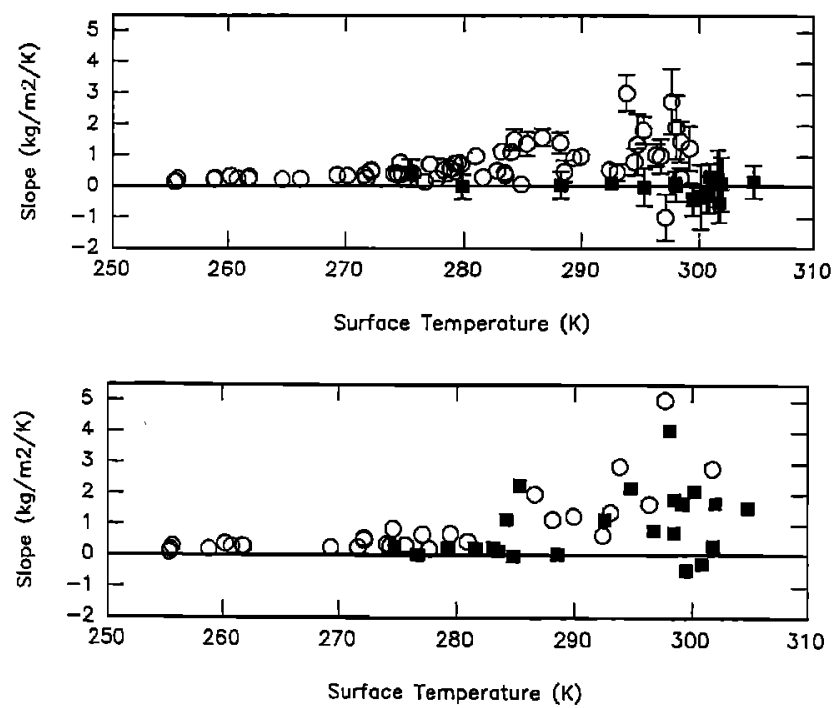

Fig. 4. Slopes of linear regression of (a) monthly and (b) annual anomalies of surface temperature and precipitable water, as a function of mean surface temperature, for each station and observation time. Error bars in (a) show two standard deviations about the slope estimates, but are not shown in (b) because they would be off scale. Where no the error bars are shown in (a), they lie within the plotted symbol. Slope estimates significantly different from zero are open circles; otherwise, solid squares are shown.

\section{Trends in Precipitable Water and Temperature}

Although our data record is relatively short, we have computed linear regression trends for 35 stations with 10 to 18 years of homogeneous observations. Most of the stations experienced an increase in both $W$ and $T_{\mathrm{s}}$, although many of these trends are not statistically significant (Table 1). In particular, $W$ and $T_{\mathrm{s}}$ increased at most of the tropical Pacific islands in our network. Gutzler [1992] also found positive trends in $W$ and $T_{\mathrm{s}}$ averaged over four tropical western tropical Pacific stations. Thus on the monthly and interannual time scale the relationship between $W$ and $T_{s}$ seems weaker than is exhibited by the "long-term" trends at some tropical stations. This tentative result should be tested with a larger number of stations and a longer time series. However, it suggests that long-term warming will be accompanied by long-term water vapor increases globally, even though on an interannual basis $W$ and $T_{\mathrm{s}}$ are not well correlated in the tropics.

\section{References}

Del Genio, A.D., A.A. Lacis and R.A. Reudy, Simulations of the effect of a warmer climate on atmospheric humidity, Nature, 351, 382-385, 1991.

Duvel, J.Ph., and F.M. Bréon, The clear-sky greenhouse effect sensitivity to a sea surface temperature change, $J$. Climate, 4, 1162-1169, 1991.

Elliott, W.P. and D.J. Gaffen, On the utility of radiosonde humidity archives for climate studies, Bull. Amer. Meteor. Soc., 72, 1507-1520, 1991.

Gaffen, D.J., Observed annual and interannual variations in tropospheric water vapor, Ph.D. Dissertation, Univ. of Maryland, 1992.

Gaffen, D.J., A. Robock, and W.P. Elliott, Annual cycles of tropospheric water vapor, J. Geophys. Res., in press.

Graham, N.E., and T.P. Barnett, Sea surface temperature, surface wind divergence, and convection over tropical oceans, Science, 238, 657-659, 1987.

Gutzler, D., Climatic variability of temperature and humidity over the tropical western Pacific, Geophys. Res. Lett., 19, 1595-1598, 1992.

Inoue, $T$., The relationship of sea surface temperature and water vapor amount to convection over the western tropical Pacific revealed from split window measurements, J. Meteor. Soc. Japan, 68, 590-606, 1990.

Raval, A., and V. Ramanathan, Observational determination of the greenhouse effect, Nature, 342, 758-761, 1989.

Rind, D., E.-W. Chiou, W. Chu, J. Larsen, S. Oltmans, J. Lerner, M.P. McCormick, and L. McMaster, Positive water vapour feedback in climate models confirmed by satellite data, Nature, 349, 500-503, 1991.

Shine, K.P., and A. Sinha, Sensitivity of the Earth's climate to height-dependent changes in water vapour mixing ratio, Nature, 354, 382-384, 1991.

Stephens, G.L., On the relationship between water vapor over the oceans and sea surface temperature, $J$. Climate, 3, 634-645, 1990.

Stephens, G.L., and T.J. Greenwald, The Earth's radiation budget and its relation to atmospheric hydrology. 1. Observations of the clear sky greenhouse effect, $J$. Geophys. Res., 96, 15311-15324, 1991.

Tjemkes, S.A., G.L. Stephens and D.L. Jackson, Spaceborne observations of columnar water vapor: SSMI observations and algorithm, J. Geophys. Res., 96, 10941-10954, 1991.

D.J. Gaffen and W.P. Elliott, NOAA, Air Resources Lab. R/E/AR, 1325 East West Hwy., Silver Spring, MD 20910. A. Robock, Dept. of Meteorology, University of Maryland, College Park, MD 20742.

(Received: May 18, 1992; accepted: August 24, 1992) 